\title{
Entre los hilos de la vida, la memoria de la infancia y la escuela deseada
}

\author{
(Among the threads of life, the memory of childhood \\ and the ideal school)
}

José Luis POLANCO ALONSO

Equipo Revista Peonza, de LIX

\begin{abstract}
RESUMEN: Un profesor que viviu intensamente a docencia e que procurou educar coas palabras máis fermosas. A acción educativa e a vida escolar están presentes nas súas obras, escritas con preocupación pola calidade literaria. Apréciase nos seus libros unha constante vontade de experimentar e de innovar, explorando recursos narrativos de moi diferente tipo: cartas, noticias de prensa, anuncios por palabras, crónicas, cancións...
\end{abstract}

PALABRAS CLAVE: escuela, pedagogía, memoria histórica, literatura infantil y juvenil, movimientos de renovación pedagógica

ABSTRACT: A professor who was passionately dedicated to teaching and sought to educate with the most beautiful words. Educational action and school life are ever-present in his works, written with special attention paid to their literary merit. In his books, there is a constant will to experiment and innovate, exploring a variety of literary resources: letters, press releases, classified ads, chronicles, songs,...

KEY WORDS: school, pedagogy, historical memory, lierature for children and adolescents, pedagogical renewal movements.

\section{Introducción}

El escenario de la escuela y los variados personajes que lo pueblan -niños y niñas, maestros, profesores y bibliotecarios, principalmente- han quedado reflejados en las novelas, cuentos, relatos y otros textos de carácter autobiográfico de Agustín Fernández Paz, escritor gallego que fue primero, y antes de nada, maestro y profesor de larga trayectoria. En escenas y evocaciones que tienen un valor emotivo y sentimental, resuenan los ecos del aula; en ellas, encontramos, además, un testimonio del devenir de la institución escolar, desde la escuela nacional-católica de la posguerra -a la que a mediados del pasado siglo asistió el propio autor-, a esta de ahora, a la que acuden los niños y niñas de hoy.

Desde la publicación de As flores radioactivas, libro con el que obtuvo el premio Merlín en 1989, a la de A neve interminable (Xerais, 2015) y La casa del miedo, (Edebé, 2016), 
han pasado casi treinta años. Treinta años dedicados a la escritura de obras de ficción. Como resultado, más de medio centenar de libros dirigidos preferentemente al público infantil y juvenil escritos en gallego y traducidos, a las otras lenguas españolas; también, al inglés, francés, árabe, portugués, italiano o coreano.

El interés de su obra reside en la calidad literaria de cuanto ha escrito. Desde el punto de vista formal, se aprecia en sus libros una constante voluntad de experimentar y de innovar, explorando recursos narrativos de muy diferente tipo; desde cartas, noticias de prensa 0 anuncios por palabras, a informes policiales, crónicas, anexos informativos, citas de poemas y canciones. Son también procedimientos habituales los juegos simbólicos, la irrupción de elementos fantásticos en la vida cotidiana, el juego con las palabras y con la estructura de las obras; sin olvidar las referencias y citas de los grandes autores gallegos, españoles y de la literatura universal, desde Cunqueiro, Valle Inclán o Ánxel Fole, a su admirado José Ángel Valente; a Poe, Melville, Conrad, y tantos otros. Hay que señalar, también, la fuerza de su imaginación creativa en una obra en la que confluyen géneros diferentes -ciencia-ficción, novela negra, aventuras o terror y misterio-, y en la que el autor mezcla la realidad y la ficción con el objetivo de captar el interés del lector.

En lo que a los temas se refiere, su obra aborda los asuntos más diversos, algunos de ellos poco frecuentados hasta entonces por la literatura destinada a niños y jóvenes. Recordemos, entre otros, la preocupación por la naturaleza, el papel de la mujer en la sociedad actual, las desigualdades económicas, el paro, la inmigración, la aceptación de la diferencia como un valor, la homosexualidad, las heridas no cicatrizadas de la Guerra Civil y la necesidad de la memoria histórica para que el pasado no caiga en las sombras del olvido. Temas que son tratados con valentía y profundidad, pero contados de manera amena y sin recurrir a falsos moralismos.

A la calidad literaria de su extensa obra hay que reconocerle el mérito de haber contribuido a desarrollar y a dignificar la literatura infantil y juvenil, a darle una mayor visibilidad en los medios de comunicación y a que exista en la actualidad una mayor sensibilidad hacia la LIJ.

No es extraño que Fernández Paz sea uno de los escritores más valorados de nuestro país y que haya cosechado los más importantes premios que se conceden en el ámbito de la LIJ. Entre otros galardones, cabe señalar el Merlín, Lazarillo, Rañolas, Raiña Lupa, Barco de Vapor, Protagonista Jove, Edebé Infantil y Juvenil, Neira Vilas, Frei Martín Sarmiento y el Premio Nacional de LIJ (1998). En el ámbito internacional, destacan las cuatro nominaciones al Astrid Lindgren, y la inclusión de sus libros en las más prestigiosas listas de la Literatura Infantil y Juvenil, desde la Lista de Honor de la CCEI, la del IBBY o el catálogo The White Ravens de la Jugenbibliothek de Munich. Además, ha sido premiado por la Federación de Libreiros y la Asociación de Escritores en Lingua Galega. En 2007, fue propuesto, por la Organización Española para el Libro Infantil (OEPLI), como candidato al Premio Astrid Lindgren; y más tarde, en 2012, al prestigioso Premio Andersen, el más alto galardón que se otorga en el ámbito de la LIJ. En reconocimiento a su trayectoria literaria, le fue otorgado, ese mismo año, el VII Premio Iberoamericano SM de Literatura Infantil y 
Juvenil. En 2013, fue investido como Doctor Honoris Causa por la Universidad de Vigo. En 2014, recibió el Premio Trasalba, otorgado por la Fundación Otero Pedrayo, en su edición XXXII, un homenaje a la literatura destinada a los lectores y lectoras más jóvenes y al compromiso de los docentes con la lengua. En 2015, recibió el Premio de los Clubs de Lectura.

\section{Los hilos de la vida}

Maestro y Licenciado en Ciencias de la Educación, Agustín Fernández Paz trabajó durante más de treinta años en centros de Educación Primaria y de Secundaria. Tirar de los hilos con los que tejió su vida nos ayuda a entender mejor su obra literaria, siempre ligada a la que fue su primera y gran vocación, la docencia, de la que nacería más tarde la necesidad de escribir.

Vayamos, pues, en busca de las raíces. Del aula de don Félix en la Escuela Graduada de Vilalba, su pueblo natal, ha dejado escritas bellas páginas. Recordemos, por ejemplo, "Los paisajes de la memoria", un texto en el que nos habla de la escuela de la posguerra, de la pobreza y del miedo en una Galicia triste y gris, como lo era la España entera de aquel tiempo.

A los trece años se traslada a Gijón para estudiar Peritaje Industrial. En 1969, marcha a Barcelona donde compagina trabajo y estudio, asistiendo a algunas clases en la Universidad; pero pueden más el teatro, la música, las amistades, las lecturas y el cine, actividades que ocupaban el escaso tiempo libre que le deja el trabajo. Dos años más tarde, decide regresar a Galicia para cursar estudios de Magisterio y Ciencias de la Educación; del 71 al 76 , vivió en A Coruña años muy intensos, los últimos de la dictadura, tiempos de agitación cultural y política. En la Escuela de Magisterio descubrió que el mundo de la educación era lo que realmente le gustaba. La confrontación de ideas ocupaba las conversaciones con los compañeros. Las nuevas revistas traían aires de cambio y propiciaban el debate. Triunfo, Cuadernos para el Diálogo, El Viejo Topo, por citar algunas, trataban con frecuencia de la situación de la escuela y de la problemática de la mujer, temas que al futuro escritor le interesaban de manera especial y que años después se verían reflejados en su obra.

Por esas fechas nacieron también algunas revistas pedagógicas, cuya lectura tuvo gran importancia para el futuro maestro. Perspectiva escolar, o Reforma de la Escuela, por ejemplo. O Cuadernos de Pedagogía; Fernández Paz recuerda la emoción al leer el primer número de esta publicación nacida en Barcelona, aventura editorial iniciada en 1975 por Fabricio Caivano y Jaume Carbonell: una apuesta por una escuela innovadora, creativa y democrática. ${ }^{1}$ En este ambiente surgió un grupo de compañeros que se reunían para hablar de las nuevas ideas y para organizar distintas actividades: un cine-club, la edición de la revista $A$ voz dos homes sen voz; o leer a Piaget, Freire, Iván Illich, Célestin Freinet, los maestros italianos del MCE; Carta a una maestra, de los alumnos de Barbiana, Gramática de la Fantasía, de Gianni Rodari.

\footnotetext{
${ }_{1}^{1}$ Agustín Fernández Paz, "Los paisajes de la memoria", en Textos literarios y contextos escolares, ed. Carlos Lomas (coord.) (Barcelona: Graó, 2008), 95.
} 
En 1974, comenzó a trabajar en el Colegio Santa Margarita (A Coruña). Por entonces, niños y niñas iban a clase en grupos separados; tendrían que pasar algunos años aún hasta que desapareciera la separación por sexos en las aulas. Con un grupo de maestros entusiastas puso en marcha una peculiar versión del Plan Dalton. Se trasladó luego al País Vasco, trabajando durante dos cursos en el Colegio Público de Guernica. De allí recuerda la utilización de la prensa en el aula, y las primeras revistas escolares que hacían con la imprenta de gelatina. Algunos maestros recordarán aquel método reprográfico que nos parecía entonces el colmo de la modernidad. Desconocíamos, pobres ignorantes, que ya antes de la guerra había sido utilizado por otros maestros, cuya trayectoria renovadora había quedado trágicamente interrumpida en el 36.

De estos primeros años de docencia procede su interés por todo lo relacionado con los estereotipos masculinos y femeninos en los cuentos tradicionales y en la literatura infantil, y por los prejuicios y actitudes sexistas en el ámbito escolar, temas que se verán ampliamente reflejados en sus libros.

Los setenta fueron años de grandes cambios políticos y sociales -el final de la dictadura, la muerte de Franco, los primeros pasos de la transición-. En el ámbito escolar, surgieron con fuerza los primeros movimientos de renovación pedagógica, impulsados por maestros comprometidos con el cambio pedagógico y social. Cuando estuvo en el País Vasco, Fernández Paz se integró en el Colectivo Adarra; y a su regreso a Galicia -trece años en el Colegio de Mugardos (A Coruña)-, en dos movimientos muy activos en cuyo ideario ocupaba un lugar importante la pedagogía Freinet: el Movemento Cooperativo da Escola Galega y el Colectivo Avantar, este más centrado en la utilización del gallego en las aulas.

En 1979, un grupo de maestros y maestras de la zona de Ferrol decidió juntarse para profundizar en el intercambio de experiencias y materiales para la renovación pedagógica y la galleguización de la enseñanza. Edicións Xerais, que acababa de nacer, les propuso la elaboración de libros de texto para la enseñanza de Lengua Gallega, haciéndose así realidad algunos de sus proyectos. Uno de los trabajos, Canles 5, obtuvo el Premio Nacional "Emilia Pardo Bazán" para libros de texto no sexistas. Más tarde, publicaría también numerosos trabajos sobre didáctica de la lengua y el fomento de la lectura, la lengua gallega y su enseñanza, la literatura infantil y juvenil, la utilización de los cómics en las aulas: Ler en galego, A maxia das palabras, A planificación lingüística nos centros educativos, Facermos cómics, Os cómics nas aulas. Su compromiso con la cultura gallega, le llevó a participar en diferentes proyectos didácticos y a formar parte de comisiones y asesorías en defensa de la lengua y la cultura gallegas. ${ }^{2}$

El fomento de la lectura fue siempre un objetivo central de su actividad en el aula. Por esta razón leyó cuanto se publicaba para niños en los años 70 y 80: los grandes autores

\footnotetext{
${ }^{2}$ Blanca Ana Roig Rechou, La literatura infantil y juvenil gallega. Seis Ilaves para entenderla mejor (Madrid: Amigos del Libro Infantil y Juvenil y Consellería de Cultura e Deporte de la Xunta de Galicia, 2008).
} 
europeos, de Astrid Lindgren a Michael Ende, pasando por Dahl, Vieira, Nöstlinger o Rodari; también algunos autores españoles de la etapa republicana, como Antoniorrobles o María Teresa León. En estas lecturas encontró, creo, el impulso para empezar a escribir. Sus primeros textos fueron algunos cuentos que utilizaba en sus clases; luego, otros para incluirlos en materiales didácticos; por fin, cuentos publicados de forma autónoma. Los primeros libros obtuvieron ya el reconocimiento: As flores radioactivas, recibió el premio Merlín en 1989; Contos por palabras, obtuvo el Premio Lazarillo en 1990, primera obra no escrita en castellano que obtenía este galardón.

Hay que recordar también las visitas a colegios e institutos, participando en proyectos como el denominado "Du plaisir de lire à la joie d'écrire", por citar alguno; éste, en colaboración con el Consulado General de España en Bayona (Francia), destinado a alumnos franceses, para el aprendizaje del español. Sin olvidar su participación en congresos y cursos de formación dirigidos a maestros, profesores y bibliotecarios. Compaginando escritura y docencia, sus últimos años como profesor los vivió en el IES Os Rosais 2, de Vigo, donde se jubiló en junio de 2007.

\section{La escuela en sus libros}

Como a Fernández Paz le gustaba decir, la literatura nace de la memoria y de la imaginación. Los libros de algunos escritores están hechos con los hilos de su propia vida, a partir de las experiencias que les tocó en suerte. Treinta años en las aulas tenían que aflorar casi por necesidad en su obra. De manera nítida unas veces, en otras, más sutil, sus libros reflejan las experiencias de este escritor que fue primero maestro. La vida escolar y los personajes que en ella se desenvuelven aparecen con frecuencia en su obra literaria; y no es extraño que así ocurra, pues, como hemos visto, no pasó sin más por las aulas, sino que en el trabajo de maestro y profesor se implicó con esfuerzo y pasión, siendo la renovación pedagógica una constante preocupación en una trayectoria profesional que vivió siempre con entusiasmo.

En consecuencia, la escuela aparece como trasfondo de varias de sus novelas, también en cuentos y en otros textos quizá menos importantes. Pero hagamos un repaso de las principales referencias. De manera explícita, el ámbito escolar lo encontramos en Trece años de Blanca, novela con la que consiguió el premio Edebé. En esta novela, una muchacha que se encuentra enferma evoca, gracias a unas fotografías, vivencias de la infancia, los amigos, el primer amor, los incidentes del colegio. Encontramos aquí las figuras de distintos maestros y maestras, algunos admirados por la joven, como Javier, el profesor que les anima a escribir y les recomienda lecturas; otros, por el contrario, como la Víbora o el Tapón, mantienen unos comportamientos censurables, profesores que abusando de la autoridad del cargo que ostentan canalizan sus frustraciones personales en ataques a los alumnos más débiles. En estas páginas, se materializa la escuela de la época, una escuela en la que perviven aún actitudes del pasado, pero en la que se vislumbra ya un ambiente nuevo en las aulas, con la participación de los alumnos, los delegados de clase y los representantes en el Consejo Escolar. 
En el corazón del bosque se desarrolla en el escenario mágico de los cuentos tradicionales. Encontramos en este libro la descripción de una escuela distinta, en la que ya no tiene cabida el clásico libro de texto y en la que aparecen los trabajos en grupo, los materiales compartidos, las fichas de trabajo, y una dinámica de clase muy distinta a la tradicional. Una niña, Raquel, y un trasgo del bosque, Derdrín, son los protagonistas; el marco, la fraga del río Eume. El propio escritor ha contado que la escena de acoso que sufre la niña en esta historia está basada en una experiencia que él mismo sufrió siendo niño en la escuela de Vilalba, su pueblo: la angustia y el miedo a las constantes amenazas del matón de la clase. Basándose en experiencias y hechos reales, el autor describe un colegio en el que el director, con la ayuda cómplice de algunos profesores, ha implantado un sistema de castigos con el que mantiene aterrorizados a los alumnos y a los otros profesores.

Avenida del Parque, 17 cuenta la historia de Marta, una niña que llega de otra ciudad, y en la nueva casa se producen misteriosos sucesos que encuentran explicación en la presencia de un fantasma que vive atrapado en ella. El libro contiene varios capítulos que hacen referencia a la vida en el instituto, y que reflejan un sistema que se sostiene en los castigos y el terror, método implantado por un director a la antigua usanza que cuenta con la ayuda cómplice de una parte del profesorado. Se observan también aquí los rescoldos de la escuela de la infancia del autor, la cerrazón intelectual y pedagógica de un sistema escolar caduco. En la ficción, el fantasma es el encargado de ejercer justicia corrigiendo la situación.

El instituto aparece como escenario en Muchachas, un conjunto de relatos protagonizados todos ellos por adolescentes. Lo escribió Fernández Paz después de asistir a un curso sobre coeducación en la Universidad de Barcelona; y es un libro escrito declaradamente "a favor de las niñas". En él, las chicas se rebelan contra los castigos físicos, el sexismo, la marginación y el racismo en el entorno educativo. En "Un curso con Ana", uno de los relatos, distintas chicas de una clase van tomando la palabra para contar las relaciones que se establecen entre los compañeros y compañeras y los comportamientos de alumnos y profesores. La actitud crítica de Ana, una chica recién llegada al centro, su enfrentamiento a los profesores, a su autoritarismo, a la rutina de la vida escolar o a la marginación de las chicas en determinadas clases, prende en algunas de sus compañeras, obligándolas a reflexionar y a tomar partido.

En "El visitante de las estrellas", otro relato de este mismo libro, Xhantl-L, un extraterrestre, llega a nuestro planeta con el objetivo de elaborar un informe para el Catálogo de Vidas del Universo. En el informe $\mathrm{n}^{\circ} \mathbf{7}$, el extraterrestre cuenta su viaje a Pontebranca, el pueblo de Laura; y describe con detalle un pequeño grupo humano, al que el extraterrestre denomina la clase, en el que la chica recibe formación: los alumnos y profesores, los procesos de aprendizaje, lo que sucede a diario en el aula. A Xhantl-L le asombra el primitivismo de las técnicas que emplean los profesores, la memorización y repetición de lo aprendido, la monotonía de la actividad diaria; también, el racismo, la marginación y la violencia verbal entre los propios compañeros de clase. ${ }^{3}$

${ }^{3}$ Un fragmento de este relato aparece en Carlos Lomas, La vida en las aulas (Barcelona: Paidós, 2002) 193-195. En algunos otros relatos sueltos incluidos en obras colectivas encontramos también el paisaje de la escuela; por 
La institución escolar alcanza un protagonismo absoluto en La escuela de los piratas, libro que obtuvo el premio Edebé, en esta ocasión en la modalidad infantil. En la línea de las fantasías rodarianas, y para regocijo de los alumnos, el edificio escolar se transforma en un barco que viaja a la deriva, río abajo, hasta llegar al mar. La travesía se convierte en una gran aventura, una experiencia única y gozosa para los alumnos: la imaginación y la participación de los niños -ellos son aquí el centro de cada actividad-, las novedades y los descubrimientos, no dejan lugar al tedio.

En esta aventura aparecen algunos profesores característicos, como doña Clara, la directora autoritaria a la que solo importa el programa y hacer méritos pensando en conseguir más adelante un puesto mejor. $O$ don Martín, el temido jefe de estudios, que parece disfrutar con el miedo de los alumnos. Pero también Ana Salgueiro, una joven profesora a la que le gusta su profesión y sabe cómo hacer para que los niños se entusiasmen con las actividades escolares. Este libro rinde tributo a los maestros que, con todas las circunstancias en su contra, trabajan para cambiar la realidad; en él encontramos de una manera expresa la visión educativa del autor.

No quiero dejar en el olvido un texto poco conocido, "Reflexións sobre a precariedade laboral", texto que el autor leyó en el congreso Prensa, escuela e infancia, celebrado en la Facultad de Periodismo de Santiago de Compostela, en julio de 2004, y que la revista Peonza publicó más tarde traducido al castellano ${ }^{4}$. En este relato, un profesor de Lengua de un colegio religioso de élite acude a un curso de formación impartido por un tal Fernández Paz. Siguiendo los consejos del ponente, entusiasmado por las experiencias pedagógicas innovadoras que ha escuchado en el curso, el maestro regresa a su clase con los periódicos bajo el brazo para utilizarlos de manera creativa. Los anuncios que pone en manos de sus alumnos desatan la creatividad de los alumnos; pero también la ira de la directora, que le despide por "conducta inmoral y depravada, inducción al lenocinio y prácticas perniciosas que atentan contra el ideario del centro". Un texto en clave de humor en el que el autor despliega su capacidad irónica y su retranca al narrar los avatares de este maestro que desea abandonar la pedagogía tradicional y abraza con entusiasmo las propuestas de la nueva pedagogía.

Mención aparte merecen dos novelas juveniles que, dada su calidad y el interés de la temática que abordan, pueden ser leídas y disfrutadas por los lectores adultos. Me refiero a Corredores de sombra y Noche de voraces sombras, dos novelas en homenaje a los maestros de la República y a los ideales humanos y pedagógicos que les servían de guía. En el momento de escribir estas novelas, el autor gallego tiene sin duda en la cabeza la larga historia de depuraciones y represión que sufrió el magisterio, la frustración y la amargura de los que fueron sus maestros en la escuela de la posguerra.

ejemplo, en VVAA, Longa lingua. Os contos da Mesa (Vigo: Edicións Xerais, 2002).

${ }^{4}$ Agustín Fernández Paz, "Reflexións sobre a precariedade laboral", Boletín Galego de Literatura no 32 (2004): 314-318. Luego, se publicó en castellano en la revista Peonza, no 108 (2014): 46-51. 
En la primera de ellas, con los trabajos de remodelación del pazo familiar, en la demolición de unos tabiques, aparece el esqueleto de un cuerpo con el cráneo agujereado. Se trata del cuerpo de un maestro republicano asesinado, cuya aparición pone en marcha los mecanismos de la narración. Clara descubre así el turbio pasado de su familia, perteneciente a "los vencedores" en la guerra. La novela va desvelando cómo el relato de la Guerra Civil repercute en la vida y en las relaciones de las nuevas generaciones, que sólo de pasada, en conversaciones familiares casuales, casi siempre inoportunas para los mayores, o en lecciones escolares muchas veces falseadas, han oído hablar de la contienda.

En la segunda novela, Noche de voraces sombras, cuyo título es un homenaje a Valente, uno de los poetas preferidos de Fernández Paz, Sara, una chica que pasa el verano con sus padres en la vieja casa familiar, siente la presencia de un muerto que quiere comunicarse con ella. De esta manera, conoce una historia silenciada durante mucho tiempo por su familia, la historia de su tío-abuelo Ramón, fallecido antes de que ella naciera, un maestro republicano cuya vida quedó truncada por la guerra. En un momento determinado, la madre de Sara le dice con amargura: "Hace años, quizá ni te acuerdes, llegaste un día del colegio contando que el profesor os había explicado la Guerra Civil: una pelea entre hermanos, en la que los dos bandos habían tenido la misma culpa; esa era la conclusión que lo resumía todo. Recuerdo que me callé y no te dije nada, dejé que esa amarga mentira siguiera extendiéndose. (...) Hoy veo claro que aquel día le di una bofetada a la memoria de mi tío, y a la de todas las personas que, como él, un día soñaron un mundo diferente. No tiene sentido el rencor, lo sé bien, pero todavía lo tiene menos el olvido y la mentira. ¿Cómo se pueden igualar las víctimas y los verdugos? Debes conocer qué pasó en aquellos años para que nunca se repita, y también para honrar la memoria de tantos sueños rotos."

En estas dos novelas, el autor levanta los velos del olvido y el miedo que ocultan realidades incómodas, y expone la necesidad de conocer y recuperar el pasado para construir sobre bases sólidas un futuro mejor y sin exclusiones.

Como decía al principio de estas líneas, la vida y la obra de Agustín Fernández Paz están estrechamente entrelazadas. La responsabilidad del maestro, la del escritor, la propia responsabilidad como persona que asume su deber ético con la sociedad en la que vive, se confunden en las distintas facetas de una vida cuyo objetivo primero fue construir un mundo mejor. No es extraño que este maestro vocacional se despidiera de sus alumnos con un discurso que llevaba como título "Cambiar o mundo e cambiar a vida"; 6 que, en el momento de la despedida, les hablara de la necesidad de los sueños y las utopías, y defendiera el derecho a la rebeldía.

\footnotetext{
${ }^{5}$ Agustín Fernández Paz, Noche de voraces sombras (Madrid: SM, 2003) 79.

${ }^{6}$ Agustín Fernández Paz: O rastro que deixamos. Edición de Isabel Soto (Vigo: Edicións Xerais, 2012), 88-96.
} 